\title{
Database Marketing Application and Barriers Faced by Firms in Service Sector in Albania A Framework For Understand Its Role In Creating Competitive Advantage
}

\author{
Evelina Bazini \\ Associated Professor, Faculty of Economy, \\ University of Vlora "Ismail Qemali" Albania. \\ evelina.bazini@univlora.edu.al \\ Aurela Ramaj \\ PhD. Candidate, Faculty of Economy, \\ University of Vlora "Ismail Qemali", Albania. \\ aurelabifsha@yahoo.ca
}

\author{
Doi:10.5901/ajis.2013.v2n9p785
}

\section{Abstract}

Competitive advantage is increasingly considered to be one of the key drivers of long-term success of an organization in today's competitive markets. Before looking for a competitive advantage a lot of work has already been done. Sales goals have been reviewed; target markets are defined, problems and opportunities are defined and a thorough marketing plan is prepared. A marketing database is a collection of valuable structured information on present and prospective customers. The information gathered includes, who they are, where they buy, when they buy and how they buy. A proper database marketing system adds value to an organization, so it plays an important role in creating the competitive advantage. This paper contributes in the discussion about the identification of the barriers faced by large and medium firms in the service sector in Albania, trying to build competitive advantage through database marketing use.

Keywords: database marketing, service sector, services, competitive advantage.

\section{Introduction}

With the amount of information that the Internet offers grows the length of time needed for their selection. We are overwhelmed by large amounts of information that is useless for us and than is problem to find those that are important to us. Therefore, knowledge discovery is playing an increasingly greater and greater role. Database Marketing (DBM) arises as a natural response to the development of electronic commerce and the growth of a large amount of information. Electronic commerce is a new economy, which places high demands for its effective use. The necessity of effective information handling solves database marketing. Its purpose is to gather data about customers, carefully save these data into databases, retrieve data from the relevant information and then use this information for improved decision-making processes ${ }^{9}$.

\section{Research methodology}

This paper is based on primary and secondary data. Primary data are results of a survey research about barriers faced by large and medium firms in the service sector in Albania, trying to build competitive advantage through database marketing use. Secondary data are results of literature review and other studies in this field. The study consisted in face to- face interviews with decision makers and marketers within 34 large and medium firms that operate in service sector in Albania. The survey was carry out as an enterprise survey, that is data collection and reporting focus on the enterprise rather than on the establishment. The sample drawn was a simple one.

\section{Database marketing}

Cooke (1994) suggests that DBM may date back as far as the 1800's, when a tailor who owned the business would record information about their customers on note cards. They would use this information to make the customer's 
experience easier and a little more personal on the next visit. Sears Roebuck \& Co. first discovered that by including a catalog with outgoing orders, their most recent customers would probably order again. Although this is a better example of a direct marketing campaign, Sears knew that the information that they had from their current customers was beneficial to their continued success (Kahan, 1998).

Companies have been utilizing informal versions of DBM for years, but it was not viewed as a marketing tool until the late 1970's and 1980's as computers became more efficient. During the early 1980's mass marketers began to apply DBM techniques by storing names, addresses, and purchasing history of existing customers. DBM initiated the concept of using individualized consumer information to benefit organizations beyond the direct mail industry. Businesses started to realize that information gathered from previous and current customers could be instrumental in designing effective marketing campaigns (Petrison, Blattberg, \& Wang, 1997).

DBM is derived from direct marketing, relationship marketing, and CRM (DeTienne \& Thompson, 1996). These researchers describe DBM as a systematic collection process of information regarding past, current and potential customers.

When accurately maintained in a database this information can help develop marketing strategies to attract new customers while fostering more personal relationships with current customers. Wright and Fletcher (1998) describe DBM as the ability to utilize the potential of computer technology to facilitate more personalized customer communication in a productive and cost effective way.

Morrison (2010) provides a similar definition of DBM stating that computer database technologies are used to create and manage customer data lists. The lists include characteristics of customers and past purchasing behaviors. Potential benefits derived from these lists are locating, selecting, targeting, servicing, and establishing customer relationships to develop the long-term value of those customers. As computer software continues to improve so do the capabilities of DBM campaigns.

In a DBM strategy, organizations gather data pertaining to customers. The data are stored, monitored, and updated regularly. It is referenced to develop more personalized relationships with current customers. It is suggested that in order to please customers, organizations must first get to know them (DeTienne \& Thompson, 1996). Kahan (1998) believes that the development of these relationships benefits the customers in terms of recognition and satisfaction, and makes the companies more profitable as a result.

Kahan (1998) further elaborates that successful database marketers use two different approaches when collecting data. Cognitive and behavioral information is gathered. In other words, the focus is on how customers appear and how they act. Some examples of cognitive analyses used on current customers include identifying demographic and psychographic information. By defining this data about current customers, the evidence can be used to create an ideal target market for potential customers.

Database marketing is the creation of a computerized marketing database using information technology and marketing to current and potential customers as individuals, in a smarter, faster and more cost effective way than competition, for their benefit and to customers profit. Businesses that venture in to database marketing are able to sell to a myriad of customers one at a time (David, 1998). This helps companies to grow comfortably making use of the sophistication of technology. A proper database marketing system adds value to an organization. But an implementation of a system which focus on technology for the sake of technology will miss the point (Cameron, 1998). It becomes valuable only if the flexible technology used promotes the easy use of the system by marketers to tackle challenging business problems.

\section{Competitive advantage}

Companies can achieve competitive advantage by conceiving new ways to conduct the activities of the value-chain in order to deliver superior value to customers, which may be defined as an act of innovation (Porter, 1985). It is seen that innovation and the competitive advantage process are inter-connected. However, empirical evidence shows that innovation leads to sustained competitive advantage has been confined to manufacturing industries. While the importance of innovation for national competitiveness and economic growth is recognized, services are viewed as innovation laggards that make little or no contribution to either productivity or growth. However, in addition to an increasing strength of competition and changes in technology, the move by organizations to a major dependence on services would point to the importance of innovation as a key component for competitive advantage for service firms (Weerawardena and McColl-Kennedy, 2002, p.13). A number of key characteristics of services differs them from products. Some of these characteristics are (Miles, 1993; Weerawardena and McColl-Kennedy, 2002, p.14):

a. a close interaction between production and consumption (co-terminality) 
b. a high information- intangible content of services products and processes

c. an important role played by human resources as a key competitive factor

d. a critical role played by organizational factors for the firm's performance.

\section{Database as a source of competitive advantage}

\subsection{Database Marketing as a Source of Strategic Competitive Advantage ${ }^{15}$}

Activities that yield sustained, better than normal returns on investment are considered competitive advantages and are strategic in nature (Porter 1985). Porter identified five strategic areas of competitive opportunity for information technology:

○ changing the basis of competition;

- strengthening customer relationships;

○ overcoming supplier problems;

- building barriers against new entrants;

○ generating new products.

Stone and Shaw (1987) see database marketing offering competitive opportunities in all these areas.

- Change the basis of competition by creating and maintaining a database and using it to: win customers from the competition; trans form how a field sales force works; provide a cost-effective means of serving small customers.

- Provide a means of strengthening customer relationships through individualized relationships with consumers that will assist companies in not only acquiring and defending customers but in stimulating revenue growth.

- Provide companies with alternative sales channels so they can overcome supplier problems and achieve a lower cost of sale, through applications such as, telemarketing, mail order, and inquiry management.

- Be a unique asset and present barriers to market entry. Conversely, database-marketing capabilities can also be used to break into new markets.

- Be used to generate new products and services. Superior customer information available through a marketing database allows a company to spot emerging trends and be first to market with new products or services. Further, the information in the database can be seen as a product in its own right.

Another strategic aspect of the competitive potential of database marketing is its ability to support organizational learning. The ability to learn faster than a firms competitors has been posited as the only true source of sustainable competitive advantage today (Slater and Narver 1995; De Tienne and Thompson 1996). A learning orientation manifests itself in a continuous collection of information about target-customers needs and competitor's capabilities and the use of this information to create continuously superior customer value. A database marketing system supports organizational learning in each of its key stages: information acquisition; information dissemination and shared interpretation. The customer database mechanizes the process of learning about customers.

\subsection{Database Marketing as a Source of Tactical Competitive Advantage ${ }^{15}$}

More often than not, however, achieving competitive advantage using database marketing refers to its use tactically rather than strategically. Commonly claimed tactical benefits (Davis 1997; Lewington et al. 1996; Berry and Maclean 1989) from the effective use of database marketing include the ability to:

o track customer buying patterns and understand their motives;

o target marketing efforts;

- vary messages to different customer groups;

- customize promotions, prices and services to individual consumers;

- reduce marketing costs and increase profits;

o improve customer retention through loyalty programs;

- coordinate the delivery of multiple services to the same customer;

- augment core offerings with valued incentives;

- personalize dialogue;

0 increase customer awareness and sales;

- minimize communication errors and breakdowns with customer;

○ efficiently monitor customer credit; 
○ predict response and project life-time value of individual customers;

- conduct market research and testing;

○ apply statistical techniques to improve understanding of customer groups; and

o track and measure the outcome of different marketing programs.

Among the firms currently using database marketing, the majority of which have not moved beyond its tactical use (Fletcher, Wheeler and Wright 1991, Roberts 1997). Fletcher, Wheeler and Wright (1991) believe the true advantages of database marketing lie in its strategic use but admit that most companies would need to make considerable changes to achieve this advantage.

\section{Obstacles to database marketing}

The literature review identifies four areas as critical to the development of competitive database marketing systems. These are:

○ environment

○ technology

○ marketing applications

- strategy versus tactics.

How organizations manage the challenges that arise in these areas determine the effectiveness of their database marketing system.

\subsection{Environmental Obstacles to Database Marketing ${ }^{15}$}

Environmental obstacles, both within and external to the organization, play a major role in the development of database marketing systems. Internal issues, or organizational barriers, are frequently more important than other barriers, but often not perceived as so by practitioners (Fletcher and Wright 1995). Organizational barriers fall into one of three major areas: cultural issues; resource issues and cognitive limits.

Today's external environment also presents numerous challenges to effective database marketing. External issues of primary concern include: data ownership; privacy; exclusionary practices and supplier interface. The impact and intricacy of external issues is compounding as companies take their database marketing strategies global.

Internal Obstacles - Cultural Issues: Research identifies five issues tied to organizational culture, which impact companies as they implement database marketing. These issues are:

○ management understanding and objectives;

○ cooperation and commitment;

○ organizational structure and ability to change;

○ decision making styles; and

○ marketing and information orientation.

\subsection{Technical Obstacles to Database Marketing ${ }^{15}$}

While firms are more cognizant of technical barriers than organizational barriers, often they still "lack critical understanding of how databases should be designed, maintained and applied to help build customer relationships" (De Tienne and Thompson 1996). When implementing database marketing, technical barriers have been found in four major areas:

- database design;

- data selection and maintenance;

- data analysis and application; and

○ 'build or buy' decision.

\section{Research results: obstacles, problems and issues faced by firms on the service sector in Albania truing to use database marketing}

According to the survey conducted to the 34 large and medium firms in the service sector in Albania that use database marketing result that:

$23 \%$ of the firms involved in the research answered that they did not use database marketing. 
Some of the firms which implemented database marketing didn't have a clear understanding of its benefits.

Only $13 \%$ of them agreed with the statement: "database marketing is generally not understood throughout our organization". They lacked an understanding of the basic concepts of relationship and database marketing, so this made them uncertain of its benefits and how to apply it to their business.

All the firms which use database marketing answered that they were aware about the importance of the need for the investment in further development of the system. They understood the need to commit resources to the system.

Due to the economic situation of the country only $38 \%$ of firms expected to substantially increase databasemarketing expenditures over the next three years even though they agreed to the fact that failure to anticipate and develop long-term investment justifications for database marketing is a barrier to its development, as well as its maintenance.

Database users firms agreed that database marketing requires skill sets many organizations do not possess, which according to Jackson and Wang (1997) are divided into four groups: marketing skills; technology skills; statistical skills and data management skills.

$48 \%$ of responding firms agree that their organizations lack internal personnel with appropriate skills for database marketing.

They also agreed to the fact that the quality of services offered by suppliers is very important in an firm's decision to adopt database marketing.

They did rely on external experts to support internal resources. $49 \%$ of them used systems/database developers, $43 \%$ used statisticians and data modelers; $18 \%$ used direct marketing agencies and other sources. While they consider these sources of support necessary to implement a database marketing strategy, they also expressed concern over the quality of the service being provided from them.

\section{Conclusions}

The objective of database marketing is to establish a one-to-one relationship with the customer or prospect in order to provide "the right stuff" - the right product, at the right price, at the right time, in the right way, to the right person. A proper database marketing system adds value to an organization, so it plays an important role in creating the competitive advantage.

This paper contributes in the discussion about the identification of the barriers faced by large and medium firms in the service sector in Albania, trying to build competitive advantage through database marketing use.

The research results reveals that firms should pay more attention to the goals setting that are aligned company's mission because just having database marketing goals is not sufficient. When they manage to do this, the potential of database marketing is at its greatest. For achieving a better result in building competitive advantage, it is important to pay a special attention to the cooperation and co-ordination among all functions in the company. Internal cooperation between the marketing and information systems departments or persons responsible for marketing and information system in the case of the firms that don't have a specific department, is especially crucial to successful database development.

Even though the firms included in the research consider external sources of support necessary to implement a database marketing strategy, they also expressed concern over the quality of the service being provided from them. They need to become aware of the fact that developing the appropriate skills within the organization, versus relying on outside expertise, is important to successful database marketing.

Organizations, like people, are limited in the amount of information they can process and comprehend. The ability to collect and store vast quantities of information has resulted in emerging mountains of data that often outstrip the organization's ability to use it effectively (Whipker and Downey 1994; Miglautsch 1995). Today, databases are used as a substitute for speaking and listening to the customer. Until organizations understand how better to value, manage, and interpret information from their databases, cognitive limitations will present obstacles to competitive advantage.

As the value of data as an asset in its own right grows, arguments over ownership are likely to accelerate. Companies who wish competitive advantage from database marketing will need to ensure they have a steady, proprietary source of consumer data.

If companies do not choose database-marketing vendors carefully, the vendors can become a major impediment to effective database marketing.

\section{References}

Berry, J. and F. Maclean. (1989). Managing the development of a customer marketing data base. Environment and Planning 21: 617- 
623.

Cooke, S. (1994). Database marketing: Strategy or tactical tool? Marketing Intelligence and Planning, 12(6), 4-7.

Foster, J, D. (1997). Maintaining Customer Relationships Through Effective Database Marketing: A Perspective for Small Retailers. Journal of Marketing Theory and Practice 5: 31-42.

De Tienne, K.B. \& Thompson, J.A. (1996). Database marketing and organizational learning theory: toward a research agenda. Journal of Consumer Marketing, 13(5), 12-34.

Fletcher, Keith and Wright, G. (1995). Organizational, Strategic and Technical Barriers to Successful Implementation of Database Marketing. International Journal of Information Management 15: 115-126.

Fletcher, Keith,. Wheeler, C and Wright, J. (1991). Database Marketing: A Channel, a Medium, or a Strategic Approach? International Journal of Advertising 10: 117-127.

Izakovič, L. Application of new information and communication technologies in marketing.

Kahan, R. (1998). Using database marketing techniques to enhance your one-to-one marketing initiatives. Journal of Consumer Marketing, 15(5), 491-493.

John, L., Leslie de Chernatony, and Brown, A. (1996). Harnessing the Power of Database Marketing. Journal of Marketing Management 12: $329-346$.

John, M. (1995). Drowning in Data? American Demographics. 12-17.

Morrison, A. M. (2010). Hospitality \& Travel Marketing, (4th Ed.). New York: Delmar.

Pinto, M, F. (2009). Database Marketing Intelligence Methodology Supported by Ontologies and Knowledge Discovery in Databases. PhD Dissertation - Doctorate in Technology Information and Information systems. Department of Information Systems. University of Minho.

Porter, M. (1985). Competitive Advantage. New York: The Free Press.

Roberts, M. (1997). Expanding the Role of the Direct Marketing Database. Journal of Direct Marketing 11: 26-35.

Seller, M and Gray,P. (1999). A survey of database marketing. Center for research on information technology and organizations, University of California, Irvine.

Slater, S.F., and John C. Narver. (1995). Market Orientation and the Learning Organization. Journal of Marketing 59: 63-74.

Stone, M. and Shaw, R. (1987). Database Marketing for Competitive Advantage. Long Range Planning 20: 12-20.

Ulicney, M. (2011). Implementation of database marketing in the private club industry. A thesis submitted to the Kent State University and Graduate School of Education, Health, and Human Services in partial fulfillment of the requirements for the degree of Master of Science.

Whipker, Linda, and David W. Downey. (1994). Integrated/database marketing: Marketing's Camelot??? Agri Marketing : 30-32.

Wright, C. D. G. \& Fletcher, K. (1998). Barriers to successful database marketing: A cross industry study. International Journal of Information Management, 18(4), 265-276.

Yilmaz, S, B. Competitive advantage strategies for SME-s in tourism sector: A case study. 